\title{
PRODUÇÃO DE Spirulina sp. (LEB18) COM ELEVADOS TEORES DE PROTEÍNA E FICOCIANINA, UTILIZANDO ÁGUA RESIDUAL DA AQUICULTURA.
}

Isabella Borges dos Anjos da Silva1; Lucas Guimarães Cardoso2; Jessica Hartwig Duarte $^{3}$; Jorge Alberto Vieira Costa3; Denilson de Jesus Assis ${ }^{4}$; Janice Izabel Druzian $^{5}$; Fabio Alexandre Chinalia ${ }^{2}$; Karina Lizzeth Pedraza Galván ${ }^{5}$

${ }^{1}$ Faculdade de Farmácia, Universidade Federal da Bahia; Salvador/BA; isaanjos99@hotmail.com

2Instituto de Ciências da Saúde, Departamento de Biotecnologia, Universidade Federal da Bahia; Salvador/BA

${ }^{3}$ Laboratório de Engenharia Bioquímica, Faculdade de Química e Engenharia de Alimentos, Universidade Federal do Rio Grande; Rio Grande/RS

${ }^{4}$ Escola de Arquitetura, Engenharia e Tecnologia da Informação, Universidade de Salvador; Salvador/BA

${ }^{5}$ Programa de Graduação em Ciências dos Alimentos, Faculdade de Farmácia, Universidade Federal da Bahia; Salvador/BA

Resumo: O objetivo foi produzir biomassa de Spirulina sp. (LEB 18) utilizando água residual da aquicultura como meio alternativo e avaliar a composição da biomassa. Os cultivos foram realizados em fotobiorreatores (1L) com $100 \%$ de água residual de aquicultura suplementada com T-25, T-50, T-75. O tratamento T-25 apresentou maiores valores de proteína $(65,73 \%)$ e ficocianina $(16,60 \mathrm{mg} / \mathrm{mL})$. Assim, o tratamento com $25 \%$ representa uma alternativa eficiente, barata e sustentável para o setor de aquicultura, produzindo biomassa de baixo custo com características diferenciadas e alto valor agregado.

Palavras-Chave: Spirulina; aquicultura; proteína.

\section{PRODUCTION OF Spirulina sp. (LEB18) WITH HIGH PROTEIN AND PHYCHOCYANINE CONTENT USING AQUACULTURE RESIDUAL WATER.}

\begin{abstract}
The objective was to produce biomass of Spirulina sp. (LEB 18) using aquaculture wastewater as an alternative means and to evaluate the biomass composition. Cultures were performed in photobioreactors $(1 \mathrm{~L})$ with $100 \%$ residual aquaculture water supplemented with T-25, T-50, T-75. Treatment T-25 presented higher values of protein (65.73\%) and phycocyanin $(16.60 \mathrm{mg} / \mathrm{mL})$. Thus, the $25 \%$ treatment represents an efficient, cheap and sustainable alternative for the aquaculture sector, producing low cost biomass with different characteristics and high added value.
\end{abstract}

Keywords: Spirulina; aquaculture; protein. 


\section{INTRODUÇÃO}

A aquicultura cresce a uma taxa constante de 4,5\% ao ano. Em 2017, essa atividade industrial atingiu uma safra global total de 83,6 milhões de toneladas, representando $55 \%$ do total de peixes utilizados para consumo humano direto [1]. 0 Relatório do Banco Mundial estima que a aquicultura produza metade da oferta mundial de pescado até 2030 [2]. Segundo Wuang et al. [3], a aquicultura intensiva utiliza grandes quantidades de água doce limpa e gera fluxos de águas residuais ricas em nutrientes que podem causar a eutrofização das águas costeiras e impactar negativamente as comunidades biológicas a jusante.

Várias tecnologias foram identificadas para o tratamento de águas residuais de aquicultura [4, 5, 6 e 7]. Conforme Kuo et al. [8], o cultivo de microalgas é frequentemente sugerido como a melhor abordagem custo-efetiva a ser aplicada em tais casos. Desta forma, Salama et al. [9] consideram que o cultivo de microalgas é um processo que pode alcançar mais de $90 \%$ de remoção de nutrientes inorgânicos com a vantagem de produzir biomassa com baixo custo e alto valor agregado. Sendo assim, Zhang et al. [10] conceituam como insumos para a produção de uma ampla gama de produtos de base biológica, no qual impulsionaria a adoção de microalgas pela indústria para a produção de alimentos para animais e aquicultura. Portanto, a Spirulina platensis ocupa uma posição de destaque no mercado global por ser uma microalga rica em proteínas ( 70\%), gorduras (3-9\%), carboidratos (15 a $30 \%$ ), $\beta$-caroteno (maior que cenouras) e vitaminas (incluindo B1, B2 e B12). Por esse motivo, a biomassa da Spirulina sp. é utilizada como suplemento alimentar para seres humanos e animais.

Alguns autores, como Pokhrel et al. [11], consideram a biomassa de $S$. platensis como um superalimento, sendo amplamente cultivada em todo o mundo, movimentando aproximadamente 30 e 60 bilhões de dólares anualmente. Diante disso, o objetivo foi produzir biomassa de Spirulina sp. (LEB18) utilizando água residual da aquicultura como meio alternativo e avaliar a composição da biomassa.

\section{METODOLOGIA}

\section{1. Água Residual da Aquicultura, Estirpe de Algas e Meio de Cultura}

O efluente aquícola foi gentilmente cedido pela Bahia Pesca S/A, localizada na Fazenda Joanes II, em Camaçari - Bahia (Nordeste do Brasil, 12ํㅜㄴ'51"S e longitude 38ำ19'27"O). A cepa de Spirulina foi isolada da Lagoa Mangueira, no sul do

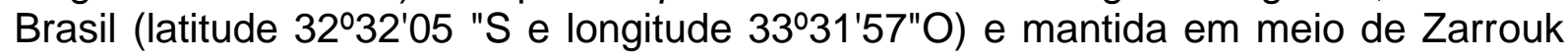
conforme a metodologia de Costa et al. [12]. As cianobactérias Spirulina sp. (LEB 18) foi obtida da Coleção de Cultura do Laboratório de Engenharia Bioquímica da Universidade Federal do Rio Grande (FURG).

\subsection{Preparação do Inoculo e Fluxograma Experimental}


O diagrama da Figura 1 mostra os passos metodológicos adotados nesta pesquisa. A água residual do cultivo de tilápia (Oreocho misniloticus) foi primeiramente suplementada com diferentes porcentagens do meio sintético de Zarrouk (ZM) NaHCO $16.8 \mathrm{~g} / \mathrm{L} ; \mathrm{NaNO}_{3} 2.5 \mathrm{~g} / \mathrm{L} ; \mathrm{NaCl} 1.0 \mathrm{~g} / \mathrm{L} ; \mathrm{K}_{2} \mathrm{HPO}_{4} 0.5 \mathrm{~g} / \mathrm{L} ; \mathrm{K}_{2} \mathrm{SO}_{4}$ $1.0 \mathrm{~g} / \mathrm{L} ; \mathrm{MgSO}_{4} \cdot 7 \mathrm{H}_{2} \mathrm{O} 0.2 \mathrm{~g} / \mathrm{L} ; \mathrm{CaCl}_{2} 0.031 \mathrm{~g} / \mathrm{L} ; \mathrm{Na}_{2} \mathrm{EDTA} 0.08 \mathrm{~g} / \mathrm{L} ; \mathrm{FeSO}_{4} \cdot 7 \mathrm{H}_{2} \mathrm{O}$ $0.01 \mathrm{~g} / \mathrm{L}$ [12]. Devido ao seu reconhecido equilíbrio nutricional, este meio de alga é o comumente utilizado para o cultivo da Spirulina sp. A Figura 1 mostra que os experimentos foram realizados apenas com a água residual da aquicultura (T-0) e com os respectivos tratamentos 25, 50 e 75\% dos nutrientes totais de Zarrouk (T-25, T-50 e T-75) seguindo proporções similares ao adotado por Kuo et al. [8] e Daneshvar et al. [13]. Após a suplementação, cada tratamento foi inoculado com Spirulina sp. (LEB 18) (no fim da fase exponencial). O crescimento foi monitorado por 7 dias, após o período a biomassa foi coletada para avaliar a produção, caracterização de biomassa (proteína, lipídios e carboidratos) e eficiência da remoção de nutrientes (utilizado para quantificar o efeito potencial do tratamento causado pelo crescimento de Spirulina sp. (LEB18)). O lipídeo extraído da biomassa foi caracterizado e a qualidade potencial do biodiesel a ser produzido foi estimada.

Figura 1. Delineamento experimental mostrando preparações médias com quantidades distintas de nutrientes e o respectivo controle com as análises subseqüentes.

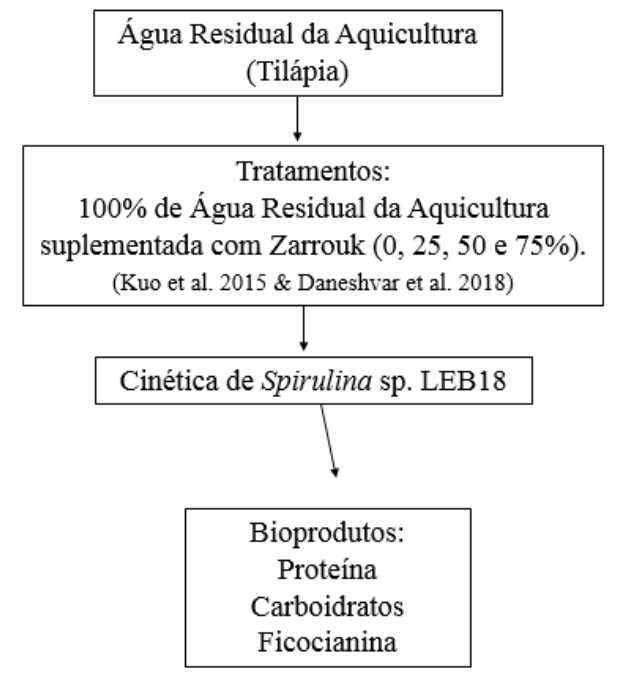

\subsection{Desenho Experimental}

A biomassa da Spirulina sp. (LEB18) foi obtida a partir de um tanque de pista $(210 \mathrm{~L})$ em cultura contínua $(0,1$ biomassa g/L) mantido com o meio Zarrouk. Os diferentes ensaios foram preparados em Erlenmeyer com um volume de trabalho de $1 \mathrm{~L}$ por meio da utilização da água residual de aquicultura $(800 \mathrm{ml})$ inoculada com a Spirulina sp. (LEB18) com concentração de $0,3 \mathrm{~g} / \mathrm{L}$ de biomassa viva. Os experimentos seguiram a metodologia proposta por Kuo et al. [8] e Daneshvar et al. [13]. 
Os tratamentos experimentais (T-25, T-50 e T-75) foram preparados com o fornecimento de fotobiorreatores de $1 \mathrm{~L}$ (água de aquacultura/inóculo) com 25, 50 e $75 \%$ do total de nutrientes médios de Zarrouk individualmente. O T-0 corresponde ao efluente aquícola sem suplementação de nutrientes e o controle ao meio sintético Zarrouk. A incubação foi realizada durante 7 dias a $30^{\circ} \mathrm{C}$ com fotoperíodo de 12 horas claro/escuro. O ar foi fornecido a todas as culturas e lâmpadas tubulares fluorescentes com uma intensidade de luz de 41,6 $\mu$ molfótons $\mathrm{m}^{-2} \mathrm{~s}^{-1}$ foram usadas como fonte de energia.

\subsection{Composição de Biomassa e Determinação de Ficocianina}

A biomassa foi recuperada do meio líquido por centrifugação $\left(4.400 \mathrm{rpm}, 4^{\circ} \mathrm{C}\right.$ por $3 \mathrm{~min}$ ), lavada com água destilada e novamente centrifugada para remoção total de sais. Posteriormente, as amostras foram congeladas em ultracongelador, liofilizadas e mantidas a $-20^{\circ} \mathrm{C}$ até sua caracterização. As proteínas foram determinadas pelo método colorimétrico elaborado por Lowry et al. [14] através da utilização de albumina de soro bovino como padrão, a partir do pré-tratamento térmico e alcalino da biomassa de microalgas. Os carboidratos foram determinados pelo método do fenol-sulfúrico desenvolvido por Dubois et al. [15] por meio da utilização de uma curva padrão de glicose. Os lipídios foram determinados pelo método de Folch et al. [16]. O método e quantificação de ficocianina seguiram método espectrométrico (densidades ópticas - OD: 652 e $620 \mathrm{~nm}$ ) sugerido por Prates et al. [17].

O método e quantificação de ficocianina determinado a partir da equação proposta por Bennett et al. [18] e Andrade et al. [19].

$$
\begin{array}{r}
\text { Ficocianina }(\mathrm{mg} / \mathrm{mL})= \\
O D_{620}-0.474\left(O D_{652}\right) / 5.34(1)
\end{array}
$$

\section{RESULTADOS E DISCUSSÃO}

A biomassa microalgal obtida no tratamento T-25 apresentou conteúdo elevado de proteína e ficocianina (65 e 16\%) quando comparado com o controle (Figura 2). Segundo Perez-garcia et al. [20], isto ocorre porque as proteínas possuem alta afinidade pelo transporte de nitrato/nitrito presente no cloroplasto. Por outro lado, Wuang et al. [3] relataram que Spirulina sp. produziu $75 \%$ menos proteína quando cultivada em águas residuais de aquicultura suplementada com 30 $\mathrm{g} / \mathrm{L}$ de $\mathrm{NaCl}$. No entanto, para Ramsundar et al. [21], o teor de proteína de Spirulina sp. foi significativamente maior do que o obtido com Chlorella sorokiniana $(25 \%)$ cultivada em águas residuais semelhantes. De acordo com Marchão et al. [22], o teor de proteína encontrado foi $50,09 \%$ para a microalga Scenedesmus obliquus cultivada a partir de água residual de cervejaria, utilizando fotobiorreatores de coluna de bolhas.

Por conseguinte, $\mathrm{Xu}$ et al. [23] pressupõem que as microalgas tendem a sintetizar lipídios como compostos de armazenamento de energia devido alto 
estresse ambiental, não aplicado ao presente estudo. De outro ponto de vista, Alva et al. [5] preveem que seja resultado da fase de crescimento logarítmico devido a presença de nitrogênio e fósforo em quantidades suficientes no meio de cultura para o crescimento das microalgas. Este resultado sugeriu que a suplementação de águas residuais da aquicultura com $25 \%$ e $50 \%$ dos ingredientes de Zarrouk não afetou a produção de lipídios dos tratamentos.

Figura 2. Composição centesimal em base seca (DW) e ficocianina de Spirulina sp. (LEB18) cultivada em $100 \%$ da água residual da aquicultura em diferentes concentrações de Zarrouk

(Controle, T-75, T-50, T-25, T-0).

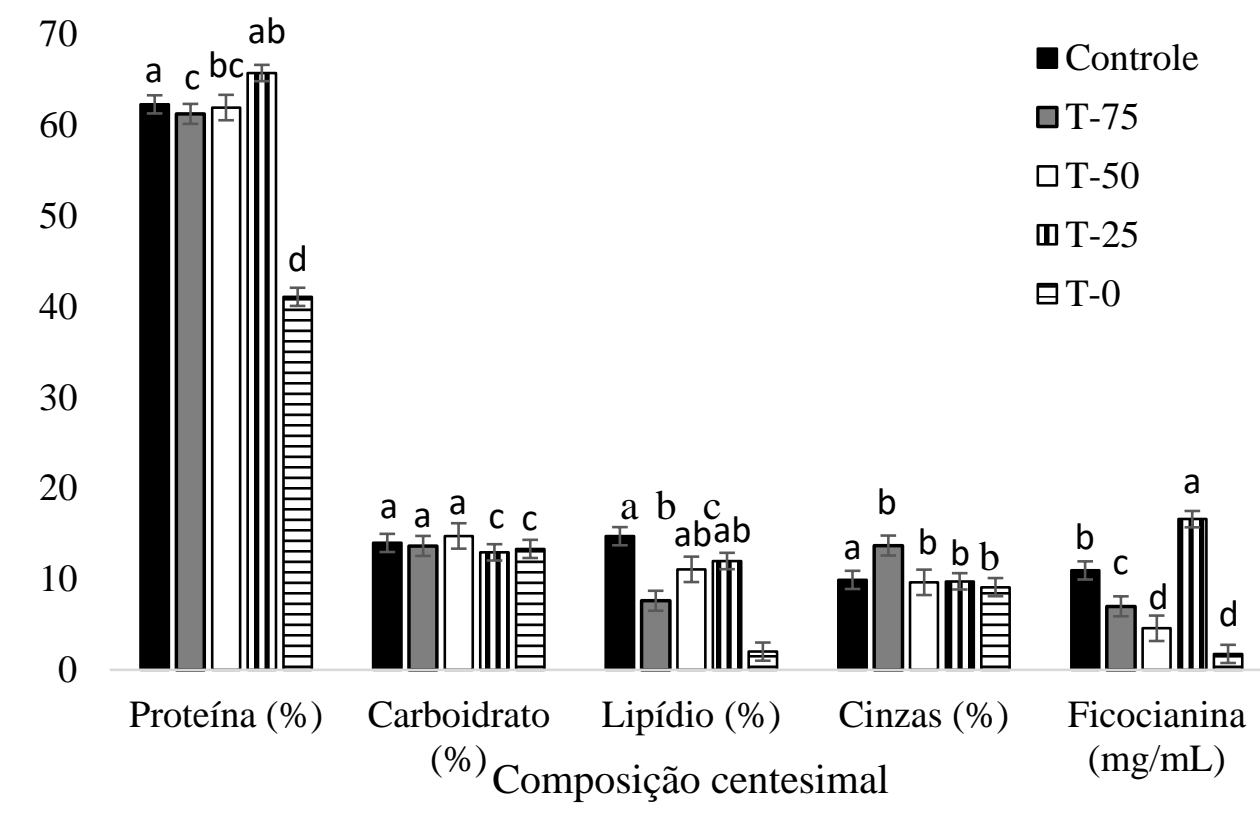

À vista disso, no tratamento T-75 o excesso de nitrogênio e fósforo possivelmente ocorreu, criando uma condição de estresse para microalgas. A presença de baixos nutrientes em T-0 pode ter reduzido a síntese lipídica. Para Mayers et al. [24], o menor teor de proteína em ambos os tratamentos está associado ao acúmulo de carboidratos devido à capacidade de manter a fixação de carbono sob estresse severo. Por outro lado, se houver alguma limitação de nitrogênio a Spirulina sp. irá acumular carboidratos [13]. Sendo assim, Wuang et al. [3] consideram que o menor acúmulo de carboidratos $(\leq 15 \%)$ pode ter associação às limitações do zinco.

A produção de ficocianina foi maior no tratamento com T-25 (Figura 2). Os resultados mostram uma produção de $0,014 \mathrm{~g}$, que é 16 vezes maior que a observada por Zeng et al. [25] em condições semelhantes. Este pigmento está diretamente associado à disponibilidade de nitrogênio e carbono durante o cultivo. Frequentemente, alta produção é observada se não houver limitação de nenhum dos compostos. Além do aspecto nutricional, Manirafasha et al. [26] observaram que a microalga é influenciada por mecanismos de hiperacumulação metabólica e expressão gênica. Ademais, para Chow et al [27], a capacidade intracelular é considerável para armazenar nitrogênio como nitrogênio solúvel e moléculas orgânicas de forma que podem ser regulada e limitada de acordo com a absorção de 
nitrogênio. A ficocianina é uma das fontes intracelulares de nitrogênio que pode ser reduzida e utilizada pelas células para persistência durante os períodos de estresse limitantes [26]. Isso explica os resultados nos outros tratamentos.

O teor de cinzas diminuiu nos tratamentos T-50, T-25 e T-0 em relação ao controle. Conteúdo de cinzas semelhante ao presente estudo foi encontrado por Vardon et al. [28] em Spirulina cultivada em liquefação hidrotérmica de matériasprimas de efluentes (10 - 12\%). De acordo com Huang et al [29], estes resultados podem se aplicar à exploração de biomassa pois as microalgas com baixo teor de lipídios e cinzas e alto teor de proteína podem ser efetivamente convertidas em bioóleo.

Segundo Zhang et al. [10], as tecnologias integradas como a Aquicultura Multitrófica Integrada (AMTI) são baseadas na aplicação de microalgas para o tratamento e reutilização de efluentes da aquicultura, que podem ser usados para obter biomassa para fins comerciais. Uma possível aplicação do tratamento T-25 aqui apresentado seria sua integração em um sistema AMTI, onde a biomassa de microalgas é posteriormente usada como alimento para outros organismos aquáticos. Estes subprodutos representam enormes potenciais como fontes alternativas de proteína aquática, devido à sua abundância, preços muito acessíveis e perfis nutricionais saudáveis para o crescimento dos peixes e também para as larvas de peixes.

Conforme Nam et al. [30], os resultados da composição química mostraram que as microalgas têm a capacidade de sofrer mudanças programáticas na partição de carbono, e assim as composições celulares, particularmente nas quantidades relativas de proteínas, lipídios e carboidratos, ocorrem em resposta às mudanças nas condições de cultivo.

\section{CONCLUSÃO}

O estudo demonstrou o desempenho de crescimento da Spirulina sp. (LEB18) em águas residuais de aquicultura suplementadas com quantidades distintas de nutrientes. No tratamento contendo $25 \%$ dos ingredientes gerais descritos no meio sintético Zarrouk, foram observados altos teores de proteína e ficocianina. Assim, a Spirulina sp. (LEB18) cultivada em água residual do cultivo de Oreochomis niloticus suplementado com $25 \%$ de Zarrouk, representa uma alternativa sustentável para melhorar as condições ambientais da prática aquícola, reduzindo os impactos das descargas de águas residuais e obtendo biomassa com baixo custo, propriedades diferenciadas e de alto valor agregado.

\section{Agradecimentos}

Todos os autores agradecem o apoio da FAPESB - Fundação de Amparo à Pesquisa da Bahia no projeto CNPQ (400710 / 2014-5), MCTIC (Ministério da Ciência e Tecnologia da Informação e Comunicação) - Brasil e Bahia Pesca. 


\section{REFERÊNCIAS}

${ }^{1}$ FOOD AND AGRICULTURE ORGANIZATION OF THE UNITED NATIONS. The State of World Fisheries and Aquaculture. Meeting The Sustainable Development Goals, Rome, 223 p., 2018.

${ }^{2}$ WORLD BANK REPORT. Fish to 2030: prospects for fisheries and aquaculture. The World Bank, Washington, DC, n. 83177, dez. 2013.

${ }^{3}$ WUANG, S. C. CHUA, P. Q. D. KHIN, M. C. LUO, Y. D. Use of Spirulina biomass produced from treatment of aquaculture wastewater as agricultural fertilizers. Algal Research, v. 15, p. 59-64, abr. 2016.

${ }^{4}$ MARKOU, G. CHATZIPAVLIDIS, I. GEORGAKAKIS, D. Cultivation of Arthrospira (Spirulina platensis) in olive-oil mill wastewater treated with sodium hypochlorite. Bioresource Technology, v. 112, p. 234-241, fev. 2012.

${ }^{5} A L V A$, S. PABELLO, M. L. MANUEL, V. LEDESMA, O. et al.Carbon, nitrogen, and phosphorus removal, and lipid production by three saline microalgae grown in synthetic wastewater irradiated with different photon fluxes. Algal Research, v. 34, p. 97-103, set. 2018.

${ }^{6}$ AZIANABIHA, K. H. A. YAAKOB, Z. ABDULLAH, S. R. S. TAKRIFF, M. S. Analysis of the elemental composition and uptake mechanism of Chlorella sorokiniana for nutrient removal in agricultural wastewater under optimized response surface methodology (RSM) conditions. Journal of Cleaner Production, v. 210, n. 14, p. 673-686, fev. 2019.

${ }^{7}$ FREIRE, I. CORTINA-BURGUeÑO, A. GRILLE, P. ARIZCUN, M. A. et al. Nannochloropsis limnetica: A freshwater microalga for marine aquaculture. Aquaculture Research, v. 459, p. 124-130, jun. 2016.

${ }^{8} \mathrm{KUO}, \mathrm{CM}$. CHEN, TY. LIN, TH. KAO, CY. et al. Cultivation of Chlorella sp., GD using piggery wastewater for biomass and lipid production. Bioresource Technology, v. 194, p. 326-333, out. 2015.

9SALAMA, E. BYONGHUN, J. SOONWOONG, C. SANGHUN, L. et al. Interactive effect of indole-3-acetic acid and diethyl aminoethyl hexanoate on the growth and fatty acid content of some microalgae for biodiesel production. Journal of Cleaner Production, v. 168, p. 1017-1024, dez. 2017.

${ }^{10}$ ZHANG, L. PEI, H. YANG, Z. WANG, X. et al. Microalgae nourished by mariculture wastewater aids aquaculture self-reliance with desirable biochemical composition. Bioresource Technology, v. 278, p. 205-213, abr. 2019.

${ }^{11}$ POKHREL, A. Soni, P. Performance analysis of different rice-based cropping systems in tropical region of Nepal. Journal of Environmental Management, v. 197, p. 70-79, jul. 2017.

${ }^{12}$ COSTA, J. A. V. COLLA, L. M. FILHO, P. D. KABKE, K. et al. Modelling of Spirulina platensis growth in fresh water using response surface methodology. World Journal of Microbiology and Biotechnology, v. 18, p. 603-607, 2004. 
${ }^{13}$ DANESHVAR, E. ANTIKAINEN, L. KOUTRA, E. KORNAROS, M. et al. Investigation on the feasibility of Chlorella vulgaris cultivation in a mixture of pulp and aquaculture effluents: Treatment of wastewater and lipid extraction. Bioresource Technology, v. 255, p. 104-110, jan. 2018.

${ }^{14}$ LOWRY, O. H. ROSEBROUGH, N. J. FARR, A. L. RANDALL, R. J. Protein measurement with the Folin phenol reagent. Journal of Biological Chemistry, v. 193, p. 265-275, nov. 1951.

${ }^{15}$ DUBOIS, M. GILLES, K. A. HAMILTON, J. K. REBERS, P. A. et al. Colorimetric method for determination of sugars and related substances. Analytical Chemistry, v. 28, n. 3, p. 350-356, mar. 1956.

${ }^{16} \mathrm{FOLCH}$, J. LEES, M. STANLEY, G. H. S. A simple method for the isolation and purification of total lipides from animal tissues. The Journal of Biological Chemistry, v. 226, p. 497-509, mar. 1957.

${ }^{17}$ PRATES, D. F. RADMANN, E. M. DUARTE, J. H. DE MORAIS, M. G. et al. Spirulina cultivated under different light emitting diodes: Enhanced cell growth and phycocyanin production. Bioresource Technology, v. 256, p. 38-43, mai. 2018.

${ }^{18}$ BENNETT, A. BOGORAD, L. Complementary chromatic adaptation in a filamentous blue-green alga. The Journal of Cell Biology, v. 58, p. 419-435, 1973.

${ }^{19}$ ANDRADE, B. B. CARDOSO, L. G. ASSIS, D. J. COSTA, J. A. V. et al. Production and characterization of Spirulina sp. LEB 18 cultured in reused Zarrouk's medium in a raceway-type bioreactor. Bioresource Technology, v. 284, p. 340-348, jul. 2019.

${ }^{20}$ PEREZ-GARCIA, O. DE-BASHAN, L. E. ESCALANTE, F. BASHAN, Y. Heterotrophic cultures of microalgae: Metabolism and potential products. Water Research, v. 45, p. 11-36, ago. 2010.

${ }^{21}$ RAMSUNDAR, P. ABHISHEK, G. SINGH, P. PILLAY, K. et al. Evaluation of wate activated sludge as a potential nutrient source for cultivation of Chlorella sorokiniana. Algal Research, v. 28, p. 108-117, 2017.

${ }^{22}$ MARCHÃO, L. M. A. DA SILVA, T. L. GOUVEIA, I. H. REIS, A. Microalgaemediated brewery wastewater treatment: effect of dilution rate on nutrient removal rates, biomass biochemical composition, and cell physiology. Journal of Applied Phycology, v. 30, p. 1583-1595, dez. 2017.

${ }^{23} \mathrm{Xu}, \mathrm{XQ}$. WANG, JH. ZHANG, TY. DAO, GH. et al. Attached microalgae cultivation and nutrients removal in a novel capillary-driven photo-bio film reactor. Algal Research, v. 32, p. 198-205, nov. 2017.

${ }^{24}$ MAYERS, J. MALMHALL-BAH, E. ALCAIDE-SANCHO, J. Identifying a marine microalgae with high carbohydrate productivities under stress and potential for efficient flocculation. Algal Research, v. 31, p. 430-442, mai. 2018.

${ }^{25} Z E N G, X$. DANQUAH, M. K. ZHANG, S. ZHANG, X. et al. Autotrophic cultivation of Spirulina platensis for $\mathrm{CO}_{2}$ fixation and phycocyanin production. Chemical Engineering Journal, v. 183, p. 192-197, fev. 2012.

${ }^{26}$ MANIRAFASHA, E. MURWANASHYAKA, T. NDIKUBWIMANA, T. RASHID, A. N. et al. Enhancement of cell growth and phycocyanin production in Arthrospira 
(Spirulina) platensis by metabolic stress and nitrate fed-batch. Bioresource Technology, v. 255, p. 293-301, mai. 2018.

${ }^{27} \mathrm{CHOW}, \mathrm{F}$. Nitrate assimilation: the role of in vitro nitrate reductase assay as nutritional predictor. In: Agricultural and Biological Sciences. São Paulo: Applied Photosynthesis, mar. 2012, v. 14, p. 105-120.

${ }^{28}$ VARDON, D. R. SHARMA, B. K. SCOTT, J. YU, G. et al. Chemical properties of biocrude oil from the hydrothermal liquefaction of Spirulina algae, swine manure, and digested anaerobic sludge. Bioresource Technology, v. 102, p. 8295-8303, set. 2011.

${ }^{29} \mathrm{HUANG}, \mathrm{Y}$. CHEN, Y. XIE, J. LIU, H. et al. Bio-oil production from hydrothermal liquefaction of high-protein high-ash microalgae including wild Cyanobacteria sp. and cultivated Bacillariophyta sp. Fuel, v. 183, p. 9-19, nov. 2016.

${ }^{30}$ NAM, K. LEE, H. H. HEO, SW. CHANG, Y. K. et al. Cultivation of Chlorella vulgaris with swine wastewater and potential for algal biodiesel production. Journal of Applied Phycology, v. 29, p. 1171-1178, dez. 2016. 